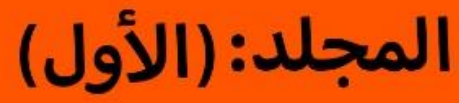

العدد: (الثالث) أبريل (2021) - الع

\title{
International Journal of Humanities and
} Social Sciences Research and Studies

\section{المجلة الدولية لبحوث ودراسات العلوم الإنسانية والاجتماعية (IJHS)}

مجلة علمية دورية محكمة تصدرها أكاديـميـة رواد التميـز للتعليم والتدريب والاستشارات والتنمية البشرية

is $: 273^{-5136}$ 
المجلة الدولية لبحوث ودراسات العلوم الإنسانية والاجتماعية (IJSH) المجلد:(الأول) العدد:(الثالث) أبريل 2021

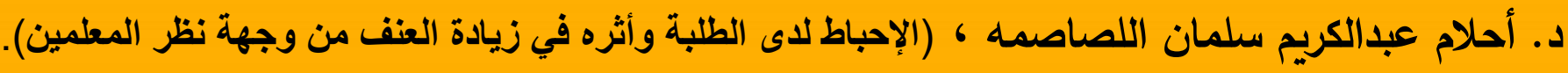

الإحباط لاى الطلبة وأثره في زيادة العنف من وجهة نظر المعلمين.

د. أحلام عبدالكريم سلمان اللصاصمه

الأردن.

ملخص.

استهرفت الاراسـة الحالية: الكشف عن العلاقة بين مستويات الإحباط لدى الطلبة

وأثره في زيادة العنف من وجهة نظر المعلمين، عند عينة لبعض المتغيرات، بلغت (50) معلم ومعلمـة مـن مدرسـة الدامخي الثانويـة للبنـات ومدرسـة الدامخي الثانويـة لذكور، للفصل الدراسـي الثاني، للعام الجامعي 2015-2016م.

ولتحقيق أهداف الدراسة، وللإجابة عن أسئلتها، تم استخدام الاستبانة، لتقيس مستويات

الإحباط، والثانية تقيس أثر زيادة العنف بين الطلبة.

أظهرت نتائج الدراسة: وجود علاقة إرتباطية إيجابية بين مستويات الإحباط وأثره في

زيـادة العنف بين الطلبة، وجمع البيانات، وتحليلها إحصائياً، ووجود علاقة إرتباطية سلبية بين مستويات الإحباط وأثره في تناقص العنف بين الطلبة جهة ثانية.

وأوصت الباحثة: بضرورة تفعيل مراكز في ضوء نتائج الدراسة، يساعد في تهيئة المناخ

التوجيـه، والإرشـاد النفسـي، والتربـوي في المدرسـة، للعمل على إعـاد بـرامج إرشـــية هادفـة

ومناسبه، وذلك لتعديل كل من مستويات الإحباط، وأثره في زيادة العنف، باعتبار هذه المتغيرات أبعادا أساسية في شخصية الطالب. 
المجلة الدولية لبحوث ودراسات العلوم الإنسانية والاجتماعية (IJSH) المجلد:(الأول) العدد:(الثالث) أبريل 2021

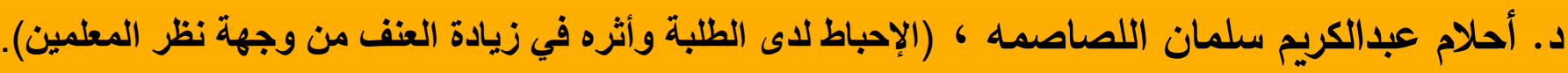

توصي هذه الدراسة - أيضاً - بضرورة إيلاء موضوعات في ضوء نتائج الدراسة، أي

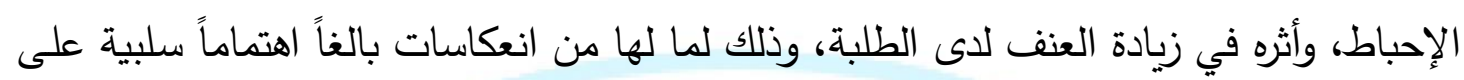

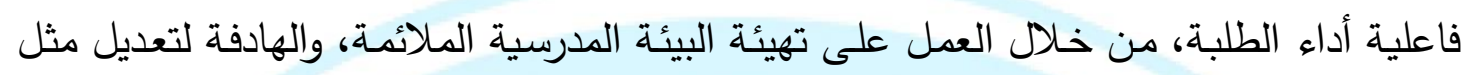
هذه السـلوكيات بها إلى المستويات المتوازنـة، لتقليـل مـن العنف، واسـتخدام وسـائل التـأثير الاجتمـاعي المتاحـة، كالمحاضـرات التثقيفيـة، والتوعوية،وعقد ورش العمل، والدورات التدريبيـة الهادفة لتقليل من أسباب الإحباط الذي يتعرض لـه الطلبة من البيئة المحيطة, ودمجهم في

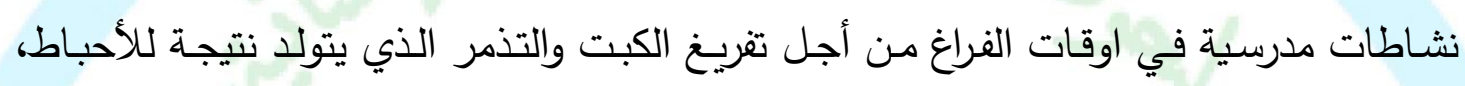
وزيادة التكيف مع الددرسة ورفع المعنويات من أجل تقوية شخصية طلبة المدرسة. الكلمات المفتاحية: (الإحباط، لدى الطلبة، زيادة العنف، وجهة نظر المعلمين).

\section{Summary.}

The current study aimed to: reveal the relationship between students' levels of frustration and its impact on the increase of violence from the teachers 'point of view. For a sample of some variables, (50) teachers from al-Damkhi secondary school for girls and al-Damkhi secondary school for males, for the second semester, for the academic year 2015- $2016 \mathrm{~m}$.

To achieve the objectives of the study, and to answer its questions, the questionnaire was used to measure levels of frustration, and the second measure the impact of increased violence among students.

The results of the study showed: There is a positive correlation between levels of frustration and its effect on increasing violence among students, data collection and statistical analysis, and the presence of a negative correlation between levels of frustration and its effect on decreasing violence among students, on the other hand. 
المجلة الدولية لبحوث ودراسات العلوم الإنسانية والاجتماعية (IJSH) المجلا:(الأول) العدد:(الثالث) أبريل 2021

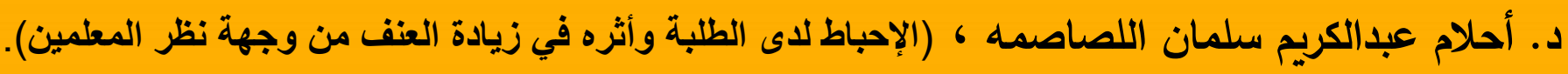

The researcher recommended: the need to activate centers in light of the results of the study, to help create a climate of guidance, psychological and educational counseling in the school, to work on preparing targeted and appropriate counseling programs, in order to modify both levels of frustration and its impact on the increase in violence, considering these variables as basic dimensions in Student personality.

This study recommends - also - that it is necessary to give topics in light of the results of the study, i.e. frustration, and its effect on increasing violence among students, because of its negative repercussions on the effectiveness of students' performance, by working to create an appropriate school environment aimed at amending such Behaviors in it to balanced levels, to reduce violence, and the use of available social impact methods, such as educational and awareness-raising lectures, holding workshops and training courses aimed at reducing the causes of frustration that students face from the surrounding environment, and integrating them into school activities in their spare time in order to empty Repression and grumbling that is generated as a result of frustration, and increasing adaptation to the school and raising morale in order to strengthen the personality of school students.

Key words: (frustration, among students, increased violence, teachers' viewpoint).

الإحباط لاى الطلبة وأثره في زيادة العنف من وجهة نظر المعلمين.

الإحباط هو شعور نفسي سيء يـلازم صـاحبه نتيجة الفشل أو تكرار الفشل في أيـة

أمور ،أو اعمال يقوم بها أو تعرضـه لموقف في الأسرة او المدرسة من قبل المعلم يولد

عنف, والإحباط وقد يؤدي في بعض الأحيان إلى المرض الجسدي (إذا لم يتلق صاحبه

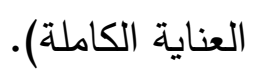


المجلة الدولية لبحوث ودراسات العلوم الإنسانية والاجتماعية (IJSH) المجلد:(الأول) العدد:(الثالث) أبريل 2021

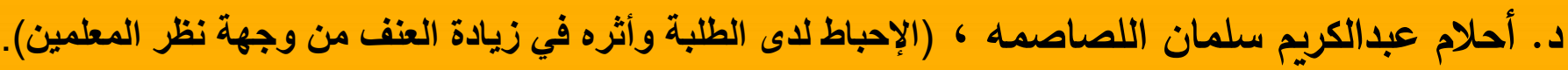

فكثير من الأشخاص من يصاب بالإحباط نتيجة قيامه بعمل ما وفثل هذا

العمل وتكراره مرة، أو مرتين وتكون النتيجة ذاتها الفشل، أو من يصاب بالإكتئاب نتيجة

الفشل الدراسي، أو الفشل العاطفي، أو فقدان أحد أفراد الأسرة، أو الأصدقاء، أو خسارة العمل ...إلخ.

وفي الحقيقة إن الإحباط إذا لم يتم علاجه والسيطرة عليه فقد يؤدي إلى تطورات غير جيدة مثل الانتحار ، أو القيام بأعمال عدوانية، أو العنف، أو اللجوء إلى أساليب

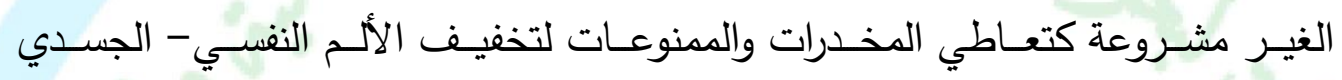
المصاحب للإحباط.

وهنا يبرز دور الأهل والمدرسة في التعامل مع مسألة الإحباط وعلاجها وتقديم

الاعم الجسدي والنفسي لحل هذه المشكلة وخاصة عندما تكون مشكلة الإحباط واقعة في القسم الأكبر من مراحل المراهقة، أو جيل الثباب وهؤلاء في كثير من الأحيان يكونون

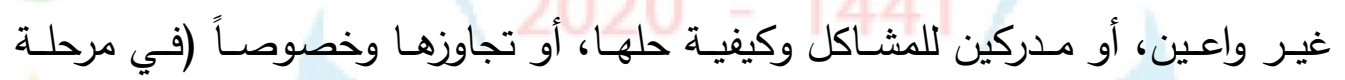
التغيرات الفيزيولوجية - النفسية) التي يمر بها المراهق، أو الثاب.

مشـكلة الدراسـة: من خلال الملاحظات اليومية، ومشاهداته لسلوكات طلبة المدرسة، تظهر بعض المؤشرات الدالة على الإحباط ، وتتمثل في كثرة الثكوى، والتذمر، وعدم الرضا، والاستياء لديهم ومظاهر العنف المختلفة، والذي قد يعزى إلى الفروق في أنماط العنف المختلفة التي تظهر لاى الطلبة، والأحداث في البيئة المدرسية. وللتحقق من صحة وجود ذلك، تتمثل مشكلة هذه الدراسـة في الإجابة عن السؤال الآتي: "هل بين مستويات الإحباط توجد علاقة دالة إحصائيا من جهة، وزيادة العنف لدى طلبة المدرسة من جهة ثانية. 
المجلة الدولية لبحوث ودراسات العلوم الإنسانية والاجتماعية (IJSH) المجلد:(الأول) العدد:(الثالث) أبريل 2021

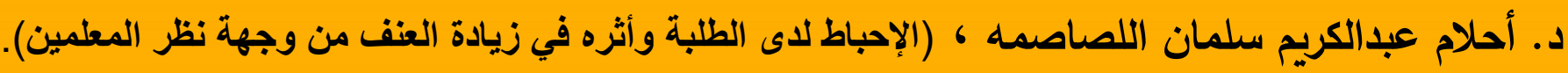

أهميـة الدراســة: مـن المؤمـل إن تقدم نتـائج الدراسـة، مزيــا النظريـة حـول هذين المتغيـرين (الإحباط، وأثره في زيادة العنف بين الطلبة) وذلك بإثراء الأدب النظري المتعلق بها في إعداد برامج من حيث وصفها, وتفسيرها التي قد تفيد لاحقا إرشادية متخصصسة، تسهم في تثكيل السلوك ألتكيفي لدى طلبة المدرسة، من خلال تقييمها، وتثخيصها، وعلاجها.

تساؤلات الاراسـة: ترتبط تساؤلات الدراسة بالأهداف التي يضعها الباحث نصب عينيه، والتي من أجلها تجرى الدراسة، وتقوم الدراسة الراهنة على تساؤل رئيسي مؤداه: هل هناك أثر الإحباط لاى الجماعات في زيادة العنف بين طلبة؟ وينبثق عنه التساؤلات الآتية:1. ما أهم أسباب الإحباط التي يتعرض لها الطلبة وعلاقتها بالعنف؟ ويتفرع عنه عدة تساؤلات

$$
\text { فرعية هي: }
$$

ما أهم المواقف المؤدية للإحباط لدى طلبة؟ ما أثكال الطرق التي تتبعها المدرسة من أجل تقليل من أسباب الإحباط المؤدي الى العنف؟

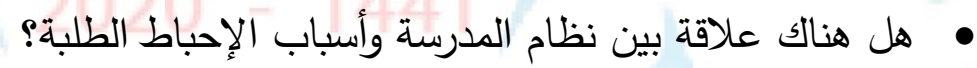
هل ينتقل الإحباط بين الطلبة بعضهم بعض ويؤثر في زيادة العنف؟

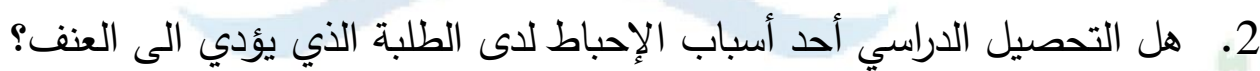
3. هل تقوم المدرسة بمساعدة الطلبة على تقليل من الضغوطات المؤدية الإحباط؟ 4. هل هناك مظاهر للاحباط وعلاقة ذلك بالعنف؟

5. هل تؤثر أساليب التتشئة على تكوين الإحباط لاى الطلبة؟ 6. هل توفر أثكال الإحباط ظروفاً مناسبة لاكتساب سلوكيات العنف لطلبة الددرسة؟ 7. ما أهم أشكال السلوكيات العنف التي تتنشر بين طلبة المدرسة؟ هربه 8. هل تتوافر احتياجات الطلبة داخل المدرسة من مؤسسات ترويحية ومؤسسات ثقافية؟ التعريفات النظرية والإجرائية لمتغيرات الاراسة.

1. الإحباط: هو الناتج عن تفاعل الطالب مع البيئة المادية - ومظاهر الاجتماعية المحيطة به في البيئة المدرسية، من خلال تعرف لـعيقات، تؤدي إلى الفشل المتكرر في إثباع حاجاته،

\section{International Journal of Humanities} and Social Sciences Research and Studies (IJHS) The print ISSN is: $2735-5128$ The online ISSN is: $2735-5136$ It is issued by the Excellence Pioneers Academy 
المجلة الدولية لبحوث ودراسات العلوم الإنساتية والاجتماعية (IJSH) المجلد:(الأول) العدد:(الثالث) أبريل 2021

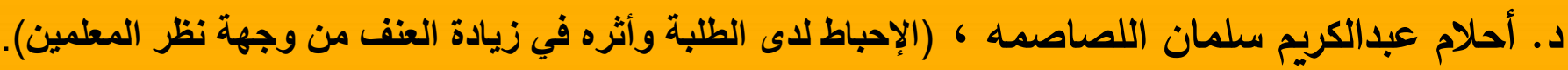

وتلبية رغباته، وتحقيق أهدافه، والتي تفضي إلى شعوره بعدم الرضـا، وكثرة الثكوى، والتذمر،

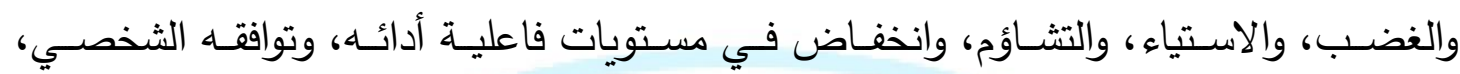
والاجتماعي(Facerman1994) فهي الدرجة التي يحصل عليها الطالب.

2. أنمـاط زيـادة العنف: هي استجابات الفرد الانفعالية للمثيرات المحيطة، والمحايدة، وغير السارة، الموجودة في البيئة المادية- الاجتماعية المحيطة به، وتتمثل في ثلاثة أنماط من الاستجابات الانفعالية، وهي: المفرط، والمتوازن (Boeco,1996).

الإطار النظري.

وبناءً على ذلك فسوف تقوم هذه الدراسة باستخدام عدة نظريات وتوظيفها بما يمكن من فهم الظـاهرة موضـوع الدراسـة " الإحباط لدى الجماعـات وأثره في زيـادة العنفـ" إن استخدام نظريات متعددة في دراسة نفس الظاهرة يسمح للباحث بمزيد من الفهم للظاهرة المدروسة، الأمر الذي يساعد على بناء بيانات الدراسة عن طريق أكثر من نظرية، والنظر إليها من أكثر من زاوية مختلفة مما يساعد على إيجاد تفسيرات متعددة للسلوك محل الظاهرة المراد دراستها. وفي هذا الصدد فإن البحث سوف ينطلق من ثلاث نظريات علمية، وهي:

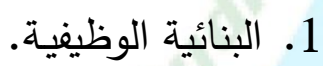

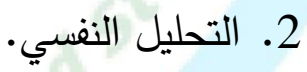

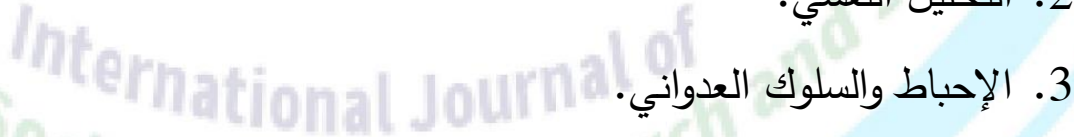
4. التعلم الاجتماعي.

يمكن استخدام المـذخل البنـائي الوظيفي لفهم الظـاهرة المدروسـة , وذلك مـن خـلال استعراض النسق الثقافي وما يحويه من أسباب الإحباط وعلاقة ذلك بالعنف ممثلة كنسق

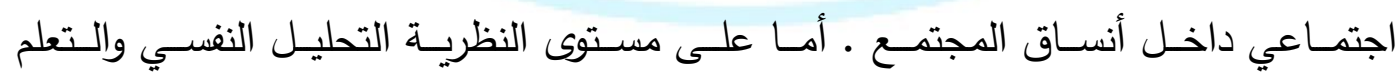
الاجتماعي. and Social Sciences Research and Studies (IJHS) The print ISSN is: $2735-5128$ The online ISSN is: $2735-5136$ It is issued by the Excellence Pioneers Academy 
المجلة الدولية لبحوث ودراسات العلوم الإنسانية والاجتماعية (IJSH) المجلد:(الأول) العدد:(الثثاث) أبريل 2021

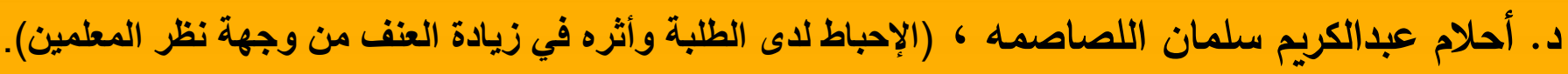

فإنه سوف يتم استعراض أسباب الإحباط للأفراد فاعلين ومتفاعلين الذي يولد سلوكيات العنف، وما تتضمنه هذه التفاعلات من اتجاهات قيمية ومعيارية، والتي من خلالها يمكن فهم مدى إحداث أثر في السلوك، ويمكن الاستفادة من نظرية الإحباط والسلوك العدواني في توضيح أهمية البيئة وتأثيرها على السلوك.

النظريـة الوظيفيـة: يستند الاتجاه الوظيفي في دراسته للمجتمع إلى افتراض أن المجتمع يمكن دراسته على أنه نسق يتألف من أجزاء تسعى متآزرة لتحقيق حالة توازن قوامها التلاؤم المتبادل

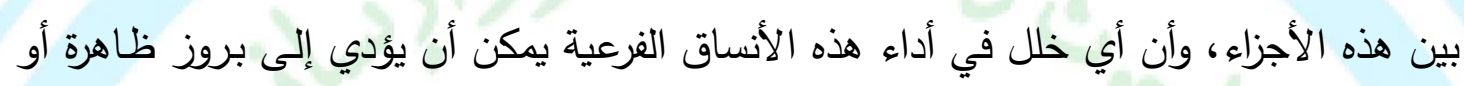
مشكلة اجتماعية في بقية أنساق المجتمع (Wallace and Wolf, 1991).

والحقيقة أنه يمكن توظيف هذه النظريـة لفهم معطيات البحث الحالي من خـال رؤيـة

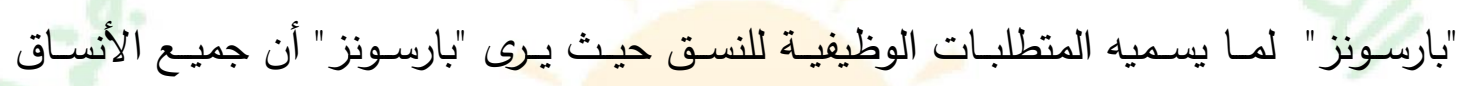

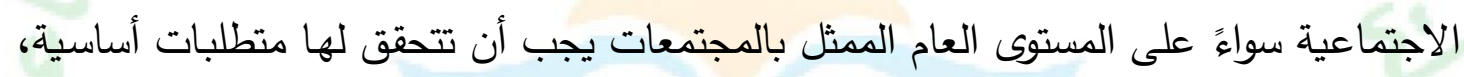
وهذه المنطلبـات لابــــــن توافرهـا حتى يستطيع النسـق الاجتمـاعي الاسـتمرار والنــو، فهي متطلبات وظيفية (التكيف، تحقيق الهذف، التكامل).

وهذه المتطلبات الوظيفية لأي نسق اجتماعي تقوم بها أنساق اجتماعية فرعية، وكل نسق

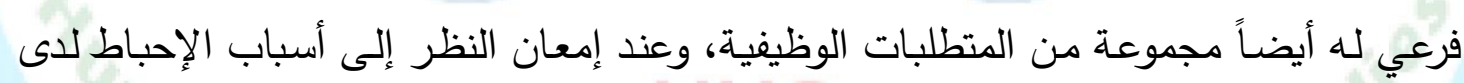

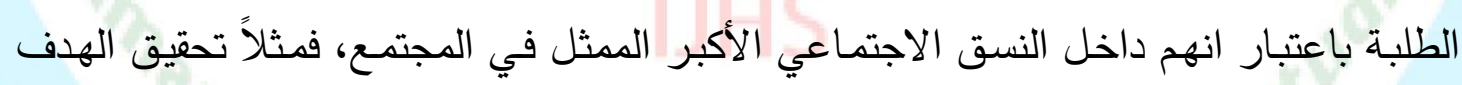
هذا المتطلب الوظيفي يدخل ضمن اعتبار "بارسونز" أن الفعل موجه نحو غاية معينة. وتحقيق الأهداف الفردية، أو الأهداف الجماعية، وعلى أي حال، فإن تحقيق الهدف يعتبر إثباعاً مطلوباً لذاته ويتحقق من خلال تراكم الفعل، والذي يأتي لاحقاً للمرحلة الإعدادية وفي مخطط الوسيلة، أو الغاية، فإن تحقيق الهدف يعبر عن الغاية والتكيف يعبر عن الوسيلة,

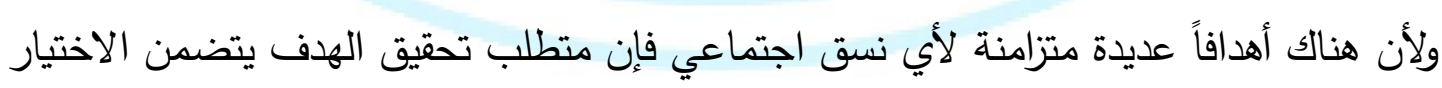

\section{International Journal of Humanities} and Social Sciences Research and Studies (IJHS) The print ISSN is: $2735-5128$ The online ISSN is: $2735-5136$ It is issued by the Excellence Pioneers Academy 
المجلة الدولية لبحوث ودراسات العلوم الإنسانية والاجتماعية (IJSH) المجلد:(الأول) العدد:(الثالث) أبريل 2021

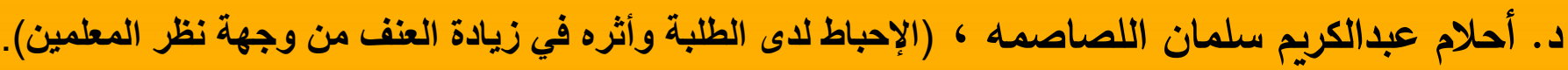

بين الأهداف المختلفة ومن ثم وضع سلم للأولويات وحشد الإمكانات والطاقات وتوجيهها نحو تحقيق الهدف.

ونجد عند عدم تحقيق الهدف هذا يؤدي الى الإحباط للى الطلبة أن لها متطلبات وظيفية لابد من إشباعها، كما أن هناك مجموعة من الأهداف ترغب في تحقيقها، ولكن يكون هناك تنظيم للأهداف التي تمثل الأولوية بالنسبة لها (والمتمثلة في دراستتا الحالية عن دور الملاحظـة) ودورهـا في إصـلاح وتقويم سلوك من خـلال حشد الإمكانـات والطاقات المتوفرة وتوجيهها نحو تحقيق هدف، الهدف الأساس، مع عدم إغفال الأهداف الفرعية الأخرى التي تمثل مراكز أقل في سلم أولوية الأهداف من حيث الأهمية محل الدراسة.

فالتكامل هذا المتطلب يتعلق بالعلاقات بين الطلبة وقدره على التواصل، ولأجل أن يعمل النمط كوحدة واحدة فإنه يجب أن تتواجد درجة معينة من التضامن بين الأنماط، ومسألة التكامل تعود إلى الحاجـة لضـمان أن يستمر نمو ذلك التواصل العـاطفي والذي ينتج عنه التضـامن والرغبة في التعاون، وهذه الروابط العاطفية يجب ألا تكون مشروطة بفائدة يتم الحصول عليها، أو مساهمة تعمل لصالح الأهداف الفردية, وهذا يقلل من الثعور بالإحباط.

نظرية التحليل النفسي: وقد نظر "فرويد" إلى العدوان باعتباره ذا منشأ داخلي، وضغط مستمر يتطلب التفريخ (التتفيس) حتى إن لم توجد إحباطات، وهنا نجد أن الحاجة إلى تتفيس العدوان قد بد

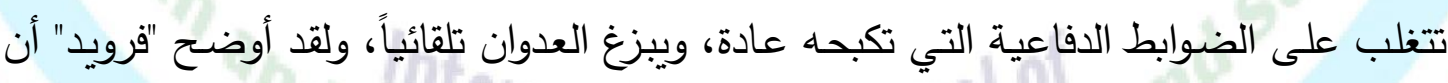
كل الأفراد لديهم دافع عدواني، ولكن الثخص السوي لا يُعبَّر عن دافعه العدواني تجاه الآخرين،

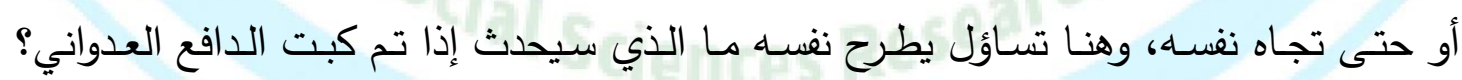
أوضح "فرويد" أنه يجب إطلاق العدوان في شكل ما. 
المجلة الدولية لبحوث ودراسات العلوم الإنسانية والاجتماعية (IJSH) المجلد:(الأول) العدد:(الثالث) أبريل 2021

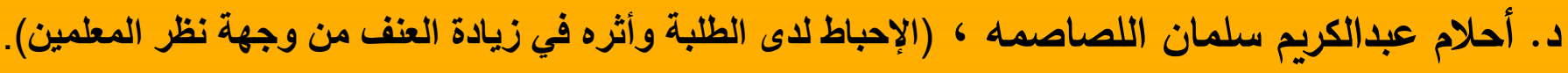

وقد يكون ذلك في شكل مباشر من خلال نشاطات اجتماعية مقبولة، مثل الرياضة والفن وغيرها. كمـا يبين "فرويد" أيضـاً أن العدوان لا يحتاج إلى أن يتم توجيهـه بشكل مباشر تجاه مصدر العدوان، فالعدوان قد يُوجَها من خلال الإزاحة نحو هدف بديل بسبب صور الكف التي لتي تعوق توجيه العدوان نحو المصدر الحقيقي له.

فالأولاد الذين يتعرضون لضرب الوالدين قد يتصرفون بشكل عدواني تجاه أقرانهم، ويؤكد"

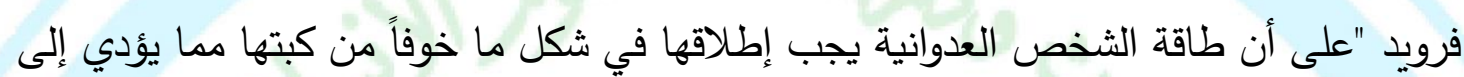
أشكال من العدوانية تصل إلى حد القتل، أو الانتحار إن كَفَّ السلوك العدواني في المواقف التي يتعرض فيها الفرد للإحباط، يشعره بإحباط جديد، لكن منع العدوان يُعتبر إحباطاً جديداً يزيد من

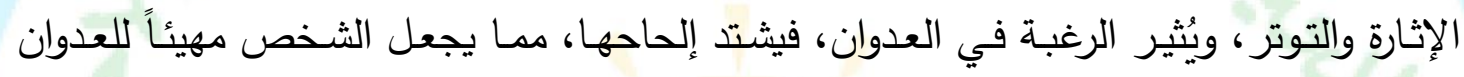
الصريح أو غير الصريح لأي إثارة بسيطة من البيئة.

يتضـح من عرض آراء "فرويد" في تفسير العدوان إلى أنه دافع غريزي يتراكم ويتجمع داخل الفرد، وإذا لم تفرغ الطاقة العدوانية المكبوتة فإن العدوان سوف يزداد لذا فالأسلوب الأفضل للتخلص من العدوان هو تفريغ هذه الثحنة لتطهير الذات بواسطة التعبير عن العدوان في سلوك

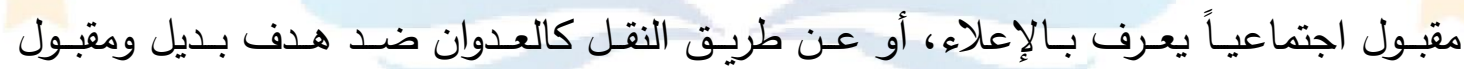

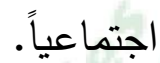

ومن هنا جعلنا "فرويد" ندرك أنه من العبث مقاومة العدوانية بطريقة مباشرة؛ إلا أننا نستطيع أن نبدل أهدافها وأثكالها بحيث تسخر للحياة أكثر منها للموت ويُشير مختلف نقاد التحليل النفسي مرة تلو الأخرى إلى أن "فرويد" أعطى الغريزة الفطريـة وزناً أكثر مما يجب؛ لذا لها يرى هؤلاء العلماء الإقلال من دور الغرائز، وإبراز المتغيرات السيكولوجية والاجتماعية التي يعتقد أنها تثكل الثخصية. 
المجلة الدولية لبحوث ودراسات العلوم الإنسانية والاجتماعية (IJSH) المجلا:(الأول) العدد:(الثالث) أبريل 2021

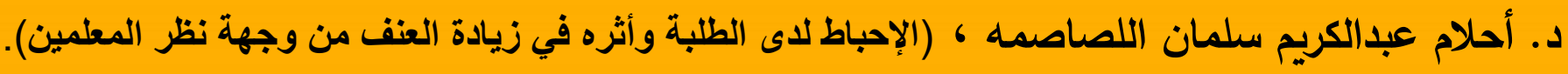

وتتفق الباحثة مع هذا الرأي؛ إذ أن مفهوم الغريزة في تفسير سلوك الإنسان مرفوض؛ لأن السلوك

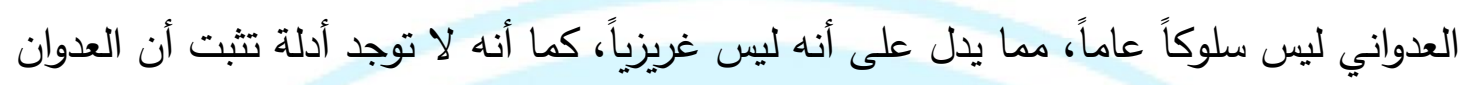
حاجة فسيولوجية كالجوع والعطش، وقد أوضحت العديد من الدراسات أن جميع الأفراد يشتركون في الحاجات الفسيولوجية للماء والأكسجين والطعام، ولكنهم في السلوك العدواني يختلفون.

نظريـة الإحبـاط والسـلوك العـدواني: مـن أثـهر علمـاء نظريـة الإحبـاط نيلـ ميللـر، روبـرت

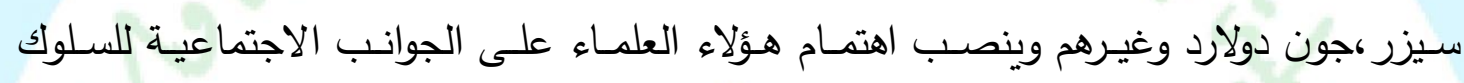
الإنساني ،وقد عرضت أول صورة لهذه النظريـة على فرض مفاده وجود ارتباط بين الإحباط والعدوان حيث يوجد ارتباط بين الإحباط كمثير والعدوان كاستجابة ،كما يتمثل جوهر النظرية في

• كل الإحباطات تزيد من احتمالات رد الفعل العدواني. كل العدوان يفترض مسبقاً وجود إحباط سابق.

فالعدوان من أثـهر الاستجابات التي تثار في الموقف الإحباطي ويشمل العدوان البدني

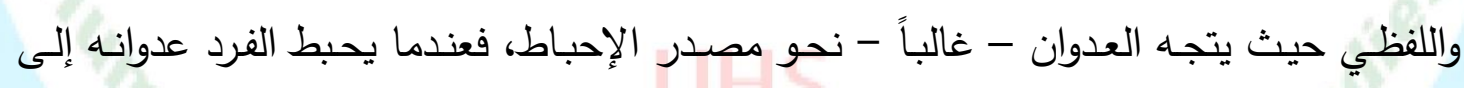

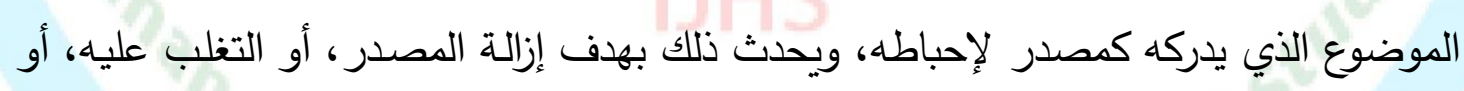
كرد فعل انفعالي للضيق والتوتر المصاحب للإحباط (كما توصل رواد هذه النظريـة إلى بعض لإسل

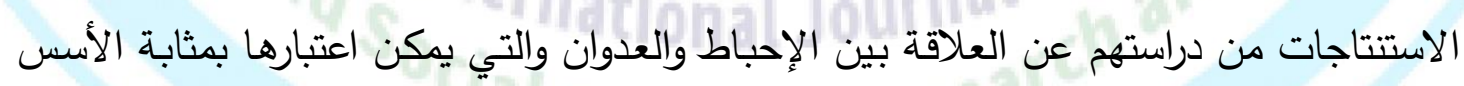
النفية المحددة لهذه العلاقة وهي:

تختلف شدة الرغبة في السلوك العدواني باختلاف كمية الإحباط الذي يواجهه الفرد ويعتبر الاختلاف في كمية الإحباط دالة لثلاثة عوامل هي: • شدة الرغبة في الاستجابة المحبطة. and Social Sciences Research and Studies (IJHS) The print ISSN is: $2735-5128$ The online ISSN is: $2735-5136$ It is issued by the Excellence Pioneers Academy 
المجلة الدولية لبحوث ودراسات العلوم الإنسانية والاجتماعية (IJSH) المجلا:(الأول) العدد:(الثالث) أبريل 2021

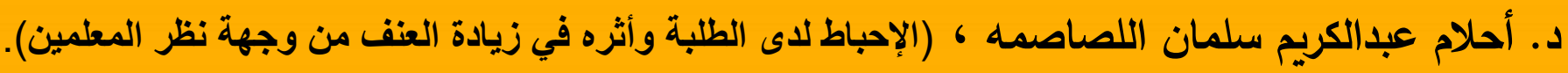

$$
\text { • مدى التدخل، أو إعاقة الاستجابة المحبطة. }
$$

تزداد شدة الرغبة في العمل العدائي ضد ما يدركه الفرد على أنه مصدراً لإحباطه، ويقل ميل

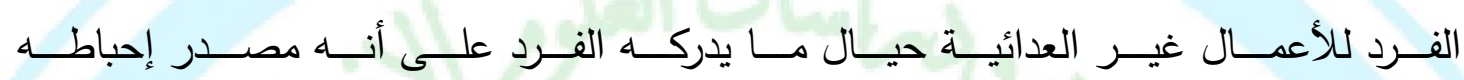
يعتبر كف السلوك العدائي في المواقف الإحباطية بمثابة إحباط أخر يؤدي إلى ازدياد ميل الفرد

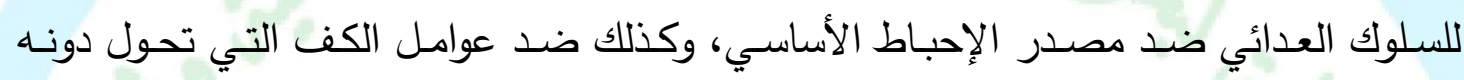
والسلوك العدائي.

على الرغم من أن الموقف الإحباطي ينطوي على عقاب للذات إلا أن العدوان الموجه ضد الذات لا يظهر إلا إذا تغلب على ما يكف توجيهه وظهوره ضد الذات، ولا يحدث هذا إلا إذا واجهات أساليب السلوك العدائية الأخرى الموجهة ضد مصدر الإحباط الأصلي عوامل كف قوية

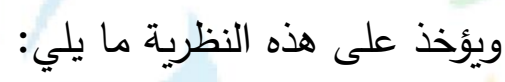

قد تبين أن ردود الأفعال العدائية يمكن أن تحدث بدون إحباط مسبق، قد تحدث الاستجابات العدوانية نتيجة للتقليد والملاحظة، كذلك فان العدوان رغم أنه ليس الاستجابة الوحيدة المدكنة للإحباط يتوقف على عدة متغيرات هي: تبرير التوقعات ومدى شدة الرغبة في الهدف إذ يزداد

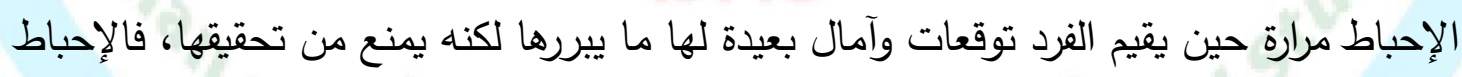
يصل إلى ذروته حين ينطوي على تبرير لتوقعات تتعلق بتحقيق هدف له أهميته أو أمل طال انتظار تحقيقه (عكاشة 1982).

نظريـة التعلم الاجتمـاعي: ويؤكد " باندورا " على أن معظم السلوك العدواني مُنَعلم من خـلد الملاحظة ثم التقليد، وهناك ثلاثة مصادر يتعلم منها الفرد بالملاحظة هذا السلوك وهي: "التأثير الأُسنرى، وتأثير الأقران، وتأثير النماذج الرمزية كالتليفزيون".

\section{International Journal of Humanities} and Social Sciences Research and Studies (IJHS) The print ISSN is: $2735-5128$ The online ISSN is: $2735-5136$ It is issued by the Excellence Pioneers Academy 
المجلة الدولية لبحوث ودراسات العلوم الإنساتية والاجتماعية (IJSH) المجلد:(الأول) العدد:(الثالث) أبريل 2021

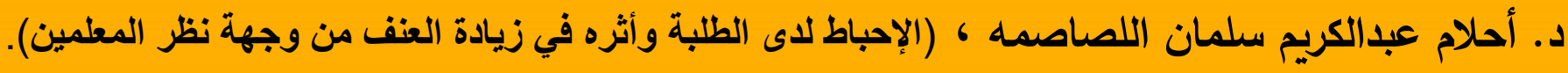

بمعنى أن الفرد يقلد النماذج التي يلاحظها والمحيطة به، فالأولاد يتعلمون السلوك العدواني من والديهم ومدرسيهم وأصدقائهج، ومن خلال مشاهدتهم لأفلام العنف بالتليفزيون، ومن خلال قراءة القصص، أو من الحكايات التي يسمعونها، ولكن أيضاً بوجود التعزيز .

كما أن لمشاهدة سلوك المدرسين العدواني أثناء معاقبتهم لتلاميذهم أثرّ على التلاميذ في

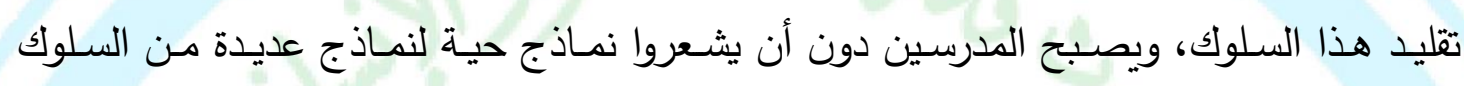
العدواني البدني واللفظي.

واتجهت بعض الدراسـات إلى تأثير الجماعـة على اكتساب السلوك العدواني، والتي

تتمثل في السلوكيات العدوانيـة للأقران، وسلوك بعض أعضـاء الجماعات التي ينتمي لها من خلال تقديم النماذج العدوانية، أو عن طريق تعزيز السلوك العدواني بمجرد حدوثه. وتعتبر النماذج العدوانية التي يتلقاهـا الثـاب منذ الصغر متمثلة في الوالدين، الأخوة، الددرسين، الأقران، الثخصيات التليفزيونية مدعمات للسلوك العدواني في حياته الخاصـة. ومن لهن هنا يتضح أن من أهم المبادئ الرئيسية التي يحدث بواسطتها التعلم التأكيد على أهمية التعلم عن

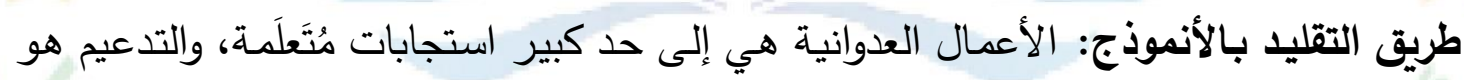
بمثابة مسهل وميسر أساسي للعدوان، فالناس تتعلم أداء سلوك معين، لأن هذا السلوك أعقبه الأبه

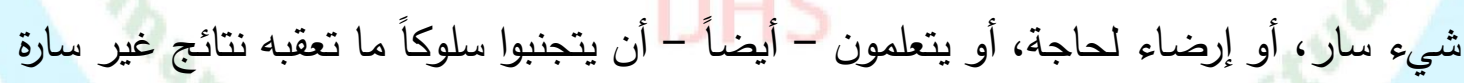

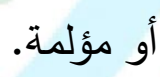
فالفرد يتعلم الانتقام والثأر مقابل الإهانـات في المدرسـة بالثجار مـع الذي أهانه أو

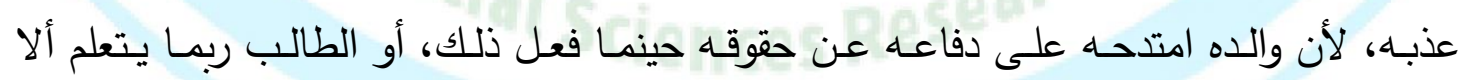

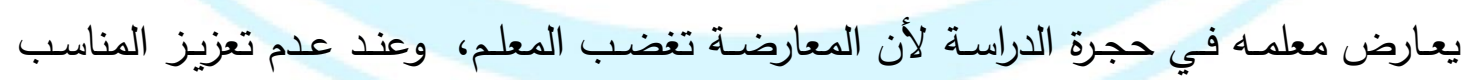
لسلوك الجيد تئثر سلبي مما تشعر بالإحباط الذي يؤدي الى السلوك العدواني. 
المجلة الدولية لبحوث ودراسات العلوم الإنسانية والاجتماعية (IJSH) المجلد:(الأول) العدد:(الثالث) أبريل 2021

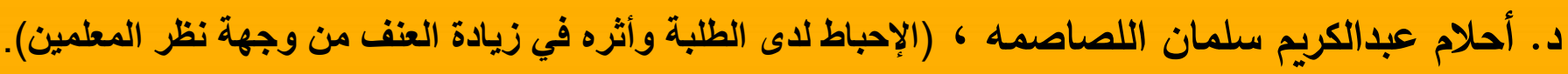

فعملية الاحتفاظ بالسلوك المكتسب تعتمد على عامل التدعيم بشكل مباشر، فالسلوك

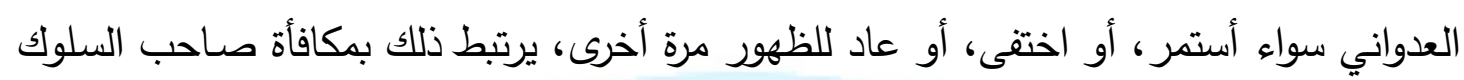

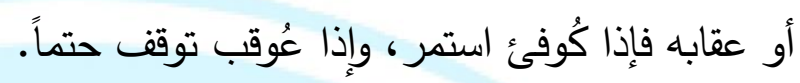

ولقد قتَّم "باندورا "عوامل التي تساعد على استمرار السلوك العدواني في ضوء نظريـة التعلم الاجتماعي وهي: - الت 1. التـعيم المباشـر الخـارجي: المتمثل بامتـاح الوالدين أو المجتهع لسلوك الفرد العدواني تعزيزات الذات: إذ يرى المعتدي أن سلوكه يجلب له نفعاً يحقق له مصلحة، أو لأفراد أسرته 2. التدعيم البديلي: المتمثل برؤية الفرد الدكاسب المادية التي يحصل عليها المعتدي، وتخلصه من الإضرار المحتملة، فيحاول هذا الفرد تقليد المعتدي في عدوانه.

3. التحرر من عقاب الذات: بأن يجرد المعتدى عليه من الصفات الإنسانية، ويقنع ذاته بأن

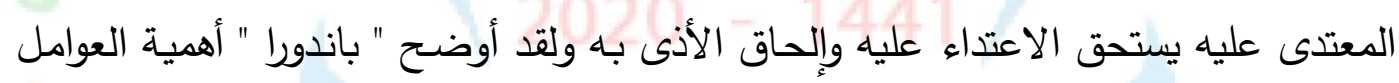
المعرفية (أفكار الناس ومعتقداتهم) في تتظيم السلوك العدواني. فقد يميل بعض الأفراد، أو القائمين بالعدوان إلى تبرير استخدامهم للسلوك العدواني الناتج

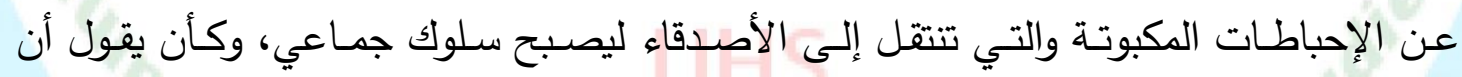
الضحية هي التي دفعت بي لاتخاذ السلوك العدواني (الوريكات 2004).

الدراسات السابقة.

تعد الدراسات السابقة من أهم المرجعيات التي يرجع إليها الباحث لمساعدته في تثخيص مشكلة الدراسة، أو استخلاص فرضياتها، أو التأكد من صحة فرضيات نظريـة ما، أو الاستفادة من بعض نتائجها في فهم دعطيات الدراسة الحالية وتفسير نتائجها، ويمكن القول إن الدراسات السابقة التي لها علاقة مباشرة بموضوع الدراسة الحالية الإحباط وعلاقتها بالعنف في هذا الجزء من الدراسة.

\section{International Journal of Humanities} and Social Sciences Research and Studies (IJHS) The print ISSN is: $2735-5128$ The online ISSN is: $2735-5136$ It is issued by the Excellence Pioneers Academy 
المجلة الدولية لبحوث ودراسات العلوم الإنسانية والاجتماعية (IJSH) المجلد:(الأول) العدد:(الثالث) أبريل 2021

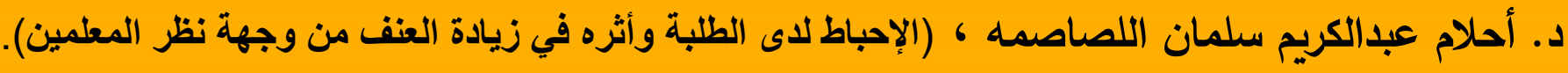

ويطرح زيدان (1995) بعداً آخر لدراسة نفس الظاهرة من خلال محاولة التعرف على الأسباب التي ربما تحول للوصول السلوك سوي فإنها تقود إلى ظواهر انحرافية خطيرة ممثلة في العود للسلوك المنحرف. ويبرز زيدان عوامل الثخصية الاجتماعية المؤثرة في سلوك العنف للى

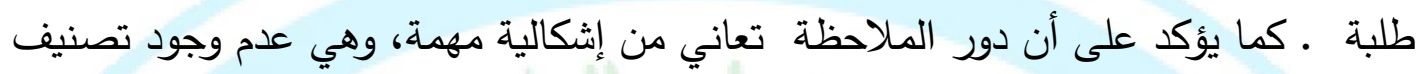
لسلوكيات الطلبـة المرغوبـة ودعمها وتحفيز تلك السلوكيات لزيـادة انتشـارها دخل حرم

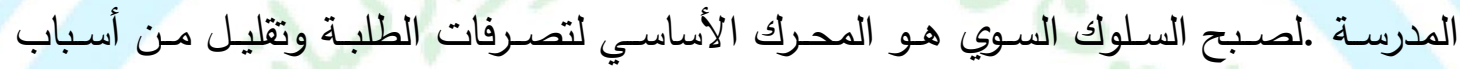
الإحباطات المختلفة وليصبح السلوك المنحرف منبوذ وغير محبب . ويعرض العتوم في كتابه حول علم النفس الجماعة (2008) على أن الجماعة هي جزء هام من هوية الفرد وشخصيته حيث لا يعقل أن يرى الناس أنفسهم في معزل عن الجماعات

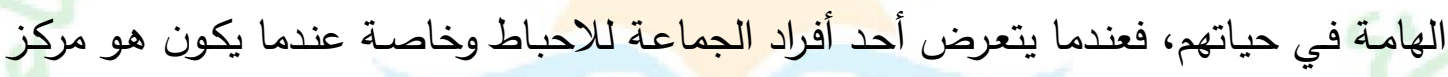
الجماعة والمسير لقرارات الجماعة, يعمل على توجيه سلوكيات أفراد الجماعة الى العنف من

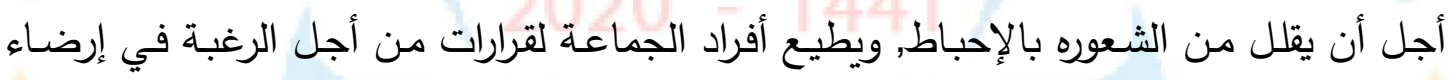
الجماعـة والحصول على القبول الاجتماعي، وعند عملية تتضمن بذل جهد مقصود من قبل شخص وعند طمس جهد احد الأفراد داخل الجماعة، أو إمكانياته يصبح لديه احباط وهذا يؤدي الى صراع داخل الجماعه نفسها.

وفي دراسة شريف صلاح الدين (2014م) ضد الإحباط، كثيراً ما يشكو لنا الآخرون من الإحباطات التي تواجههم وتدمر حياتهم فنقف مكتوفي الأيدي، ولا ندري ماذا نفعل، ويكون

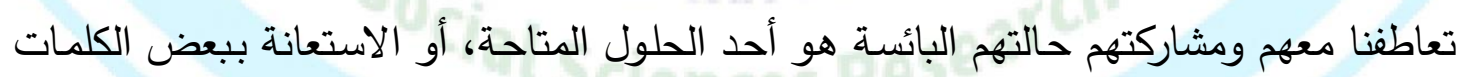
المألوفة التي لم تعد تجدي نفعاً هرباً من الاستماع إليهم في صمت، كل هذه الأفعال ستصبح مكبوتات تؤدي العنف، لذا سيكون تفاعلك مع احباطات الآخرين إيجابياً وفعلاً.

وفيمـا يتعلقق بوصف أن الجماعـات أحد الأوسـاط التي يأخذ منهـا الأفراد السلوكيات المختلفة ويؤثر على نفسية الأفراد عندما يعاني أحدهم من كبت والإحباط ليغير من سلوكهم

\section{International Journal of Humanities} and Social Sciences Research and Studies (IJHS) The print ISSN is: $2735-5128$ The online ISSN is: $2735-5136$ It is issued by the Excellence Pioneers Academy 
المجلة الدولية لبحوث ودراسات العلوم الإنساتية والاجتماعية (IJSH) المجلد:(الأول) العدد:(الثالث) أبريل 2021

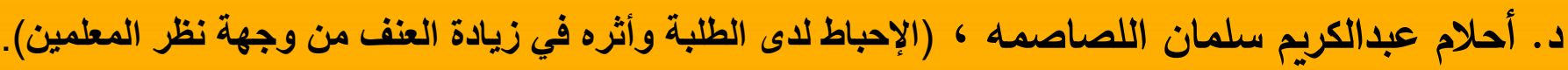

وليعزز من السلوك العدواني المسبب للعنف كما أظهرت دراسـة (الجيلاني 2008) تحت عنوان التنظيم والجماعات, يحدث تفاعل بين سلوك الثخص .وسلوك الجماعات إما يكتسب منها ليؤثروا على سلوكه, أو يؤثر هو على سلوكهم, وفي بعض الأحيان تحقق إشباع الحاجات، والتقليد يحدث أكثر بين أفراد تلك الجماعات, لهذا يصبح سلوكهم مبرر .

ومن الدراسات التي اهتمت بموضوع علاج مشكلة الإحباط النفسي لكردي (2010) وهي توضح أن الإحباط الذي يتعرض لها الانسان بصورة مستمره في حياته اليومية، ويعد من أخطر

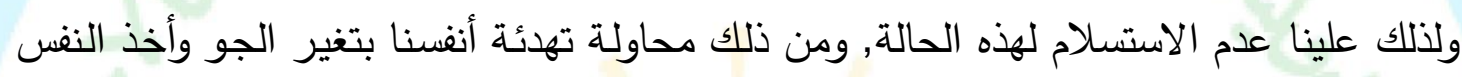
العميق في الهواء الطليق، أو القيام بالاشياء التي نحب القيام بها عادة في أوقات فراغنا, لانها بالفضفضة إلى شعورنا بالرغبة في ذلك دون مكابره, ولنذكر أنفسنا - دائماً - بأن دوام الحال من المحال - أحياناً - عندما نضع الخطط, فإننا مباشرة نفكر في الحل ونتجه إليه دون دراسة كافية للخيارات الممكنه، وعندما تصـاب بالإحباط فإنك تتجه الى العصف الذهني, وهي دراسة لجميع الحلول والخيارات الممكنـة، وبالتـالي قد تكتثف طرق اكثر فعاليـة بقليـل مـن الجهـ والتنكير. المنهجية والإجراءات. - ات.

يتـاول هذا الفصل منهجيـة الدراسـة, وتوضيح لمجتمع وعينـة الدراسـة, وطريقـة بنـاء أداة الدراسـة, والإجراءات تطبيق أداة الدراسلة, وأساليب المعالجـة الإحصـائية المستخدمة في تحليل البيانات, وتتمثل تلك الإجراءات فيما يلي: والاء لترات

\section{منهجية الاراسة.}

تعد هذه من الدراسات الوصفية التي تسعى إلى توضيح الإحباط لدى الطلبة وأثره في زيادة العنف من وجهة نظر المعلمين, فهي بذلك تبحث في أحد المشكلات الاجتماعية التي يعاني منها المجتمع, وذلك لتحديد أبعادها ومحاولة الوصول إلى نتائج قد تسهم في إيجاد حلول

\section{International Journal of Humanities} and Social Sciences Research and Studies (IJHS) The print ISSN is: $2735-5128$ The online ISSN is: $2735-5136$ It is issued by the Excellence Pioneers Academy 
المجلة الدولية لبحوث ودراسات العلوم الإنسانية والاجتماعية (IJSH) المجلد:(الأول) العدد:(الثالث) أبريل 2021

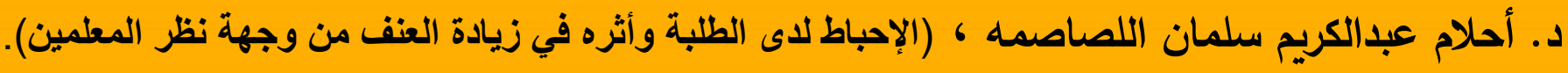

لها وتعد هذه الدراسـة أيضـاً من الدراسـات الكميـة حيث استخدمت الأسـاليب الإحصـائية الكمية لتحليل البيانات وإجراء المقارنات وتحديد طبيعة العلاقة بين المتغيرات.

وبذلك فإن منهج الدراسة هو المنهج الوصفي المسحي "التحليلي", لكون هذا المنهج هو الأنسب لدراسـة الظواهر المجتمعيـة وإبرازهـا كمـا هـي في بيئتهـا مـن خـلاد استخدام الأدوات المناسبة لجمع البيانات من عينة الدراسة، وتحليلها بالأساليب الإحصائية لإيجاد الاستنتاجات ذات الدلالمة والمغزى بالنسبة للمشكلة المطروحسة في الدراسـة ولتحقيق أهدافها والخروج بالتوصيات المناسبة. مجتمع الدراسة وعينتها.

يتكون مجتمع هذه الدراسة من المعلمين الددرسة الدامخي لبنين والبنات الثانوية لكونها من المؤسسات التي يكثر بها هذه الظاهرة، ولأغراض هذه الدراسة بطريقة عشوائية منتظمة من مجتمع الدراسة تثكل ما نسبته 10\% من طلبة، وفيما يلي عرض لخصائص عينة الدراسة: 1. توزيع أفراد عينة الاراسة حسب الجنس: للتعرف على خصائص أفراد عينة الدراسة حسب الجنس تم إيجاد التكرارات والنسب المئوية, والموضحة في الجدول (1). الجدول رقم (1) توزيع أفراد عينة الدراسة حسب متفير الجنس.

\begin{tabular}{|c|c|c|}
\hline النسبة المئوية \% & التكرار & 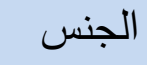 \\
\hline 54 & Mationat Jout 27 & انثى \\
\hline 46 & Tuciences & ذكر \\
\hline 100.0 & 50 & المجموع \\
\hline
\end{tabular}

يظهر من الجدول (1) أن: أفراد عينة الدراسة من الذكور قد شكلوا ما نسبته 46\% من حجم العينة, بينما شكلت الإناث ما نسبته 54\%. and Social Sciences Research and Studies (IJHS) The print ISSN is: $2735-5128$ The online ISSN is: $2735-5136$ It is issued by the Excellence Pioneers Academy 
المجلة الدولية لبحوث ودراسات العلوم الإنسانية والاجتماعية (IJSH) المجلد:(الأول) العدد:(الثالث) أبريل 2021

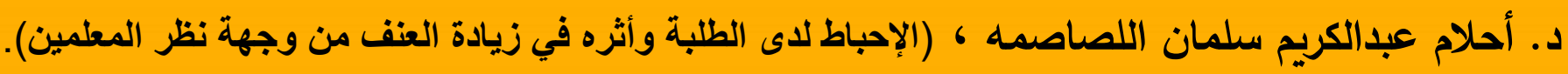

2. توزيع أفراد عينة الاراسة حسب السنة الخبرة: للتعرف على خصائص أفراد عينة الدراسة حسب السنة الخبرة تم إيجاد التكرارات والنسب المئوية, والموضحة في الجدول (2). جدول (2) توزيع أفراد عينة الدراسة حسب متغير السنة الخبرة.

\begin{tabular}{|c|c|c|}
\hline النسبة المئوية \% & ا التكرار & السنة الخبرة \\
\hline 14 & 7 & $4-1$ \\
\hline 44 & 22 & 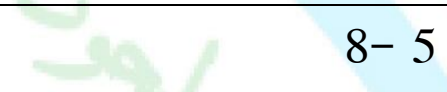 \\
\hline$\sqrt{20}+x^{2}$ & 21 & 8 فاكثر \\
\hline 100.0 & 50 & المجموع \\
\hline
\end{tabular}

يظهر من الجدول (2) أن: أفراد عينة من السنة 1 - 4 قد شكلوا ما نسبته 14\% من حجم العينة , بينما شكل نسبة السنة 5 - 8 ما نسبته 44 \% ، وشكلت السنة 8 فاكثر نسبته 42\%. 3. توزيع أفراد عينة الاراسة حسب الصفوف التي تدرسها: للتعرف على خصائص أفراد عينة الدراسة حسب الصفوف التي تدرسها تم إيجاد التكرارات والنسب المئويـة، والموضحة في

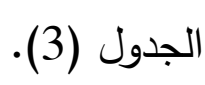

الجدول (3) توزيع أفراد عينة الدراسة حسب الصفوف التي تدرسه.

\begin{tabular}{|c|c|c|}
\hline النسبة المئوية \% & التكرار & الصفوف \\
\hline$\% 60$ & & الاساسية \\
\hline$\% 40$ & 20 & الثانوية \\
\hline 100.0 & 50 & وع \\
\hline
\end{tabular}

يظهر مـن الجدول (3) أن: أفراد عينـة الدراسـة مـن الاساسية نسبتها 60\%، ونسبة الثانويـة $\% 40$

\section{International Journal of Humanities} and Social Sciences Research and Studies (IJHS) The print ISSN is: $2735-5128$ The online ISSN is: $2735-5136$ It is issued by the Excellence Pioneers Academy 
المجلة الدولية لبحوث ودراسات العلوم الإنساتية والاجتماعية (IJSH) المجلد:(الأول) العدد:(الثالث) أبريل 2021

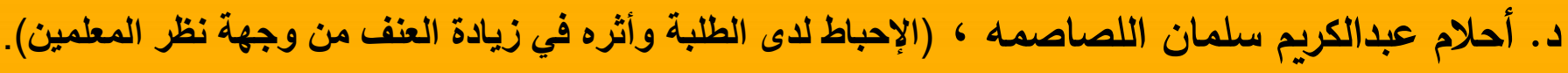

4. توزيع أفراد عينة الاراسة حسب المساق الذي تدرسـه: للتعرف على خصائص أفراد عينة

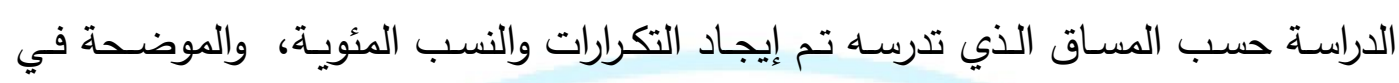

$$
\text { الجدول (4). }
$$

الجدول (4) توزيع أفراد عينة الاراسة حسب المساق الذي تدرسه.

\begin{tabular}{|c|c|c|}
\hline النسبة المئوية \% & التكرار & المساق \\
\hline$\% 40$ & 20 & $390 /$ \\
\hline$\sqrt{2-x+2}$ & 30 & الإنسانية \\
\hline$x^{2}$ & 50 & المجموع \\
\hline
\end{tabular}

يظهر من الجدول (4) أن: أفراد عينة الدراسة من المساق العلمية نسبتها 40\%، ونسبة المساق الإنسانية 60\%

أداة الاراسـة: بعد إجراء المسح المكتبـي والاطـلاع على الجانب النظري والدراسـات السـابقة المتعلقة بموضوع الدراسة, تم بناء وتطوير استبانة تكونت من الأجزاء التالية:

الجزءء الأول: ويتضـمن خصـائص أفراد عينة الدراسـة طبقاً للمتغيرات التالية: (الجنس, السنة الخبرة، والمساق الذي تدرسه, والصفوف التي تدرسه).

الجزء الثاني: ويتضمن 20 فقرة تقيس تصورات أفراد عينة الدراسة حول مجموعة من السلوكيات المختلفة وعلاقة بالإحباط لاى الجماعات واثره في زيادة العنف.

وتم تصنيف جميع إجابات فقرات الاستبانة للجزء الثاني حسب أوزانها رقمياً على النحو التالي: - n

$$
\text { 2. 1. كبيرة ويمثل (3 درجات). }
$$

\section{International Journal of Humanities} and Social Sciences Research and Studies (IJHS) The print ISSN is: $2735-5128$ The online ISSN is: $2735-5136$ It is issued by the Excellence Pioneers Academy 
المجلة الدولية لبحوث ودراسات العلوم الإنساتية والاجتماعية (IJSH) المجلد:(الأول) العدد:(الثالث) أبريل 2021

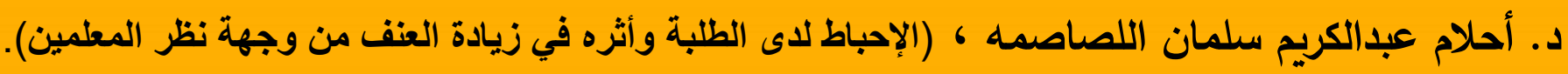

$$
\text { صدق وثبات أداة الدارة: تم التحقق من صدق أداة الدراسة من ثلاث جوانب هي: }
$$

1. التحقق مـن الصدق الظـاهري: تم التحقق من الصدق الظـاهري لأداة الدراسـة من خـلد

الاستبيان وتتميز بوضوح وسهولة عباراتها صياغتها اللغوية الوارد في الاستبانة.

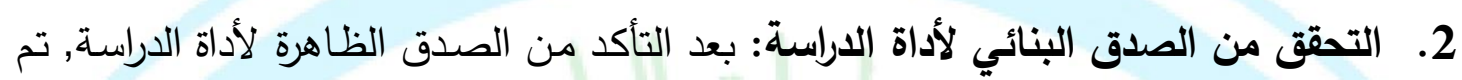

تحديد مدى التجانس الداخلي للأداة من خلال حساب معاملات الارتباط بين درجة كل عبارة

$$
\text { والدرجة الكلية لعبارة البعد التي تتنمي إليه, في الجدول (5). }
$$

جدول (5) التحقق من الصدق البنائي باستخدام معاملات الارتباط بين كل فقرة من فقرات.

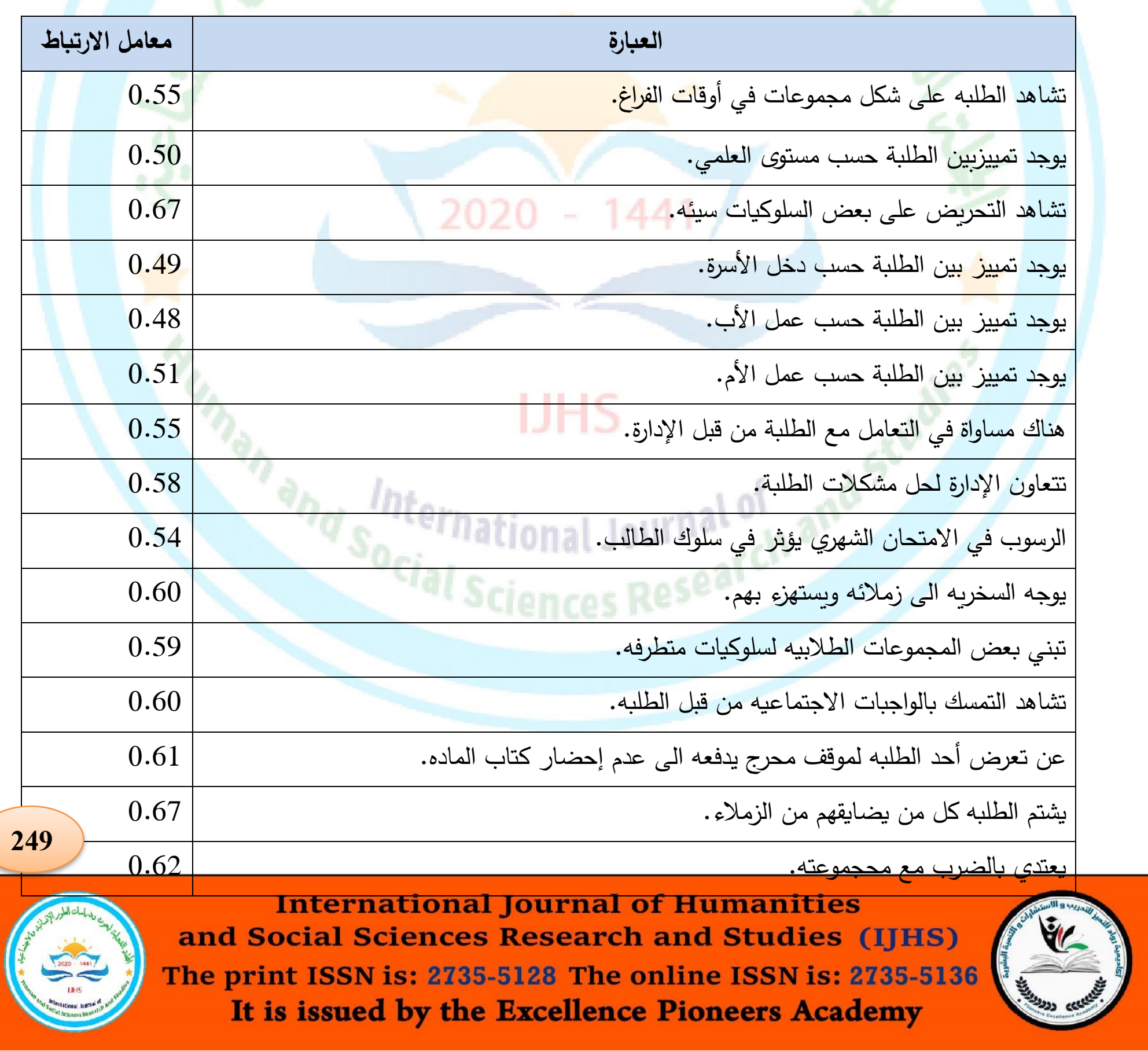


المجلة الدولية لبحوث ودراسات العلوم الإنسانية والاجتماعية (IJSH) المجلد:(الأول) العدد:(الثالث) أبريل 2021 د. أحلام عبدالكريم سلمان اللصاصمه ، (الإحباط لاى الطلبة وأثره في زيادة العنف من وجهة نظر الألماعلة المعلمين).

\begin{tabular}{|c|c|}
\hline 0.65 & يلجا إلى سرقةٌ ممتلكات الطلبه مع مجموعتاه عند تعرضه لموقف محرج. \\
\hline 0.58 & يستخدم ألفاظ غير لائقه مع زملائه. \\
\hline 0.69 & يستعمل الجماعه من أجل التعالي على الزملاء والفاخر عليهم لإرضاء نفسه. \\
\hline 0.67 & يعتمد لرد الإساءة اللفظيه بأساءة بدنية. \\
\hline 0.71 & يهدد الزملاء بالضرب خارج حرم المدرسه مع الجماعه عند تعرضه لموقف محبط. \\
\hline 0.58 & 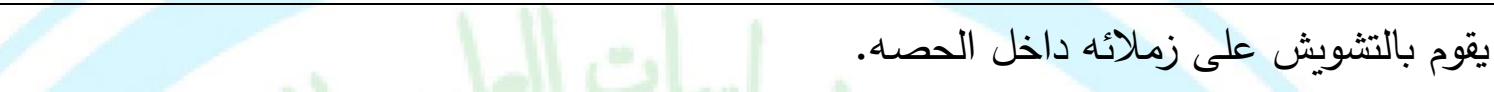 \\
\hline 0.59 & يقوم بالمغالاه في اصدار الإحكام على زملائه لمجرد الاختلاف معهم بالرأي بعد تعرضه منهم لموقف محرج. \\
\hline 0.49 & 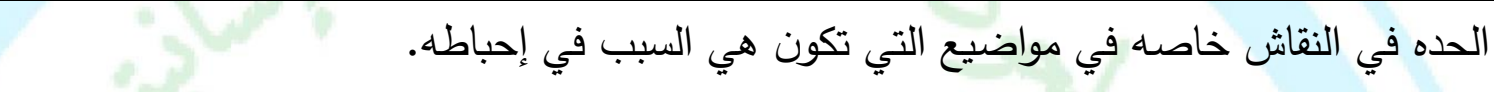 \\
\hline 0.66 & تكوين شله في المدرسه لإثارة الفوضى كرد على إحباطه. \\
\hline 0.49 & الاعتداء على ممتلكات المدرسه. \\
\hline 0.55 & التعامل بأسلوب غير لائق مع المدرسين والإداره. \\
\hline 0.56 & 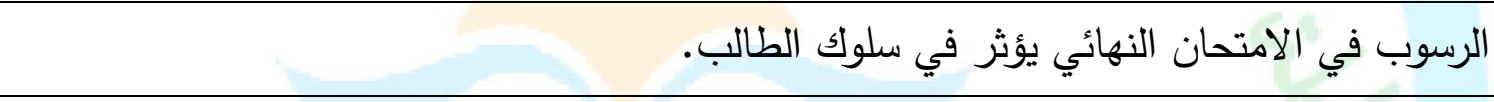 \\
\hline 0.58 & 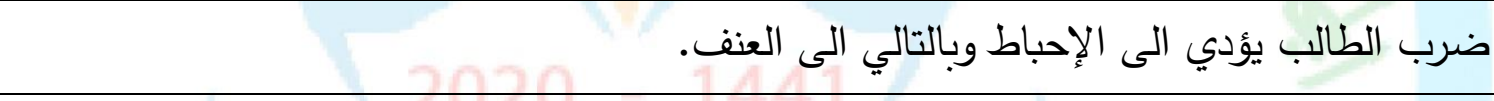 \\
\hline 0.60 & 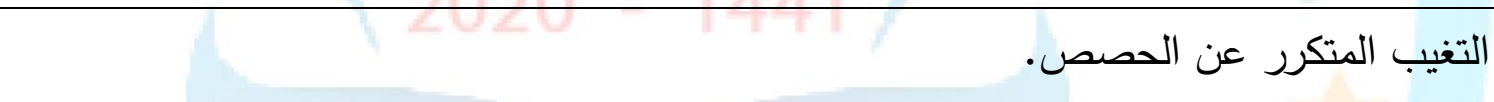 \\
\hline
\end{tabular}

$$
\text { زات دلالة إحصائية عند مستوى دلالة (0.01>p }
$$

أظهر النتائج في الجدول (5) أن: معاملات الارتباط بين درجات كل عبارة من عبارات مع الدرجة الكلية تتراوح (0.71 و 0.49) وهي معاملات ارتباط دالة إحصائياً عند مستوى دلالة (0.01) وبهذه يتضـح الاتساق الداخلي, مما يؤكد تحقق الصدق البنائي لأداء الدراسة, ويشير

$$
\text { إلى ثبات النتائج. }
$$

نتـائج الدراسـة: يتضمن الفصل الإجابة عن أسئلة الدراسـة وفقا لـا أظهرتـه نتائج المعالجات الإحصائية, حول إجابات أفراد عينة الدراسة نحو الدراسة.

عرض نتـائج الأسـئلة: ومن أجل الإجابة عن هذه الأسئلة تم إيجـاد المتوسطات الحسـابية والانحرافـات المعياريـة لإجابـات أفراد عينـة الدراسـة حـول السلوكيات والجدول (6) يبين هذه and Social Sciences Research and Studies (IJHS) The print ISSN is: $2735-5128$ The online ISSN is: $2735-5136$ It is issued by the Excellence Pioneers Academy 
المجلة الدولية لبحوث ودراسات العلوم الإنسانية والاجتماعية (IJSH) المجلد:(الأول) العدد:(الثالث) أبريل 2021

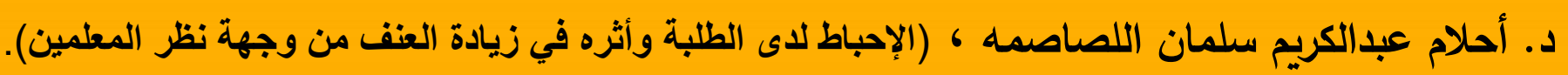

الجدول (6) المتوسطات الحسابية والانحراف المعيارية ومستوى تصورات

أفراد عينة الاراسة حول السلوكيات.

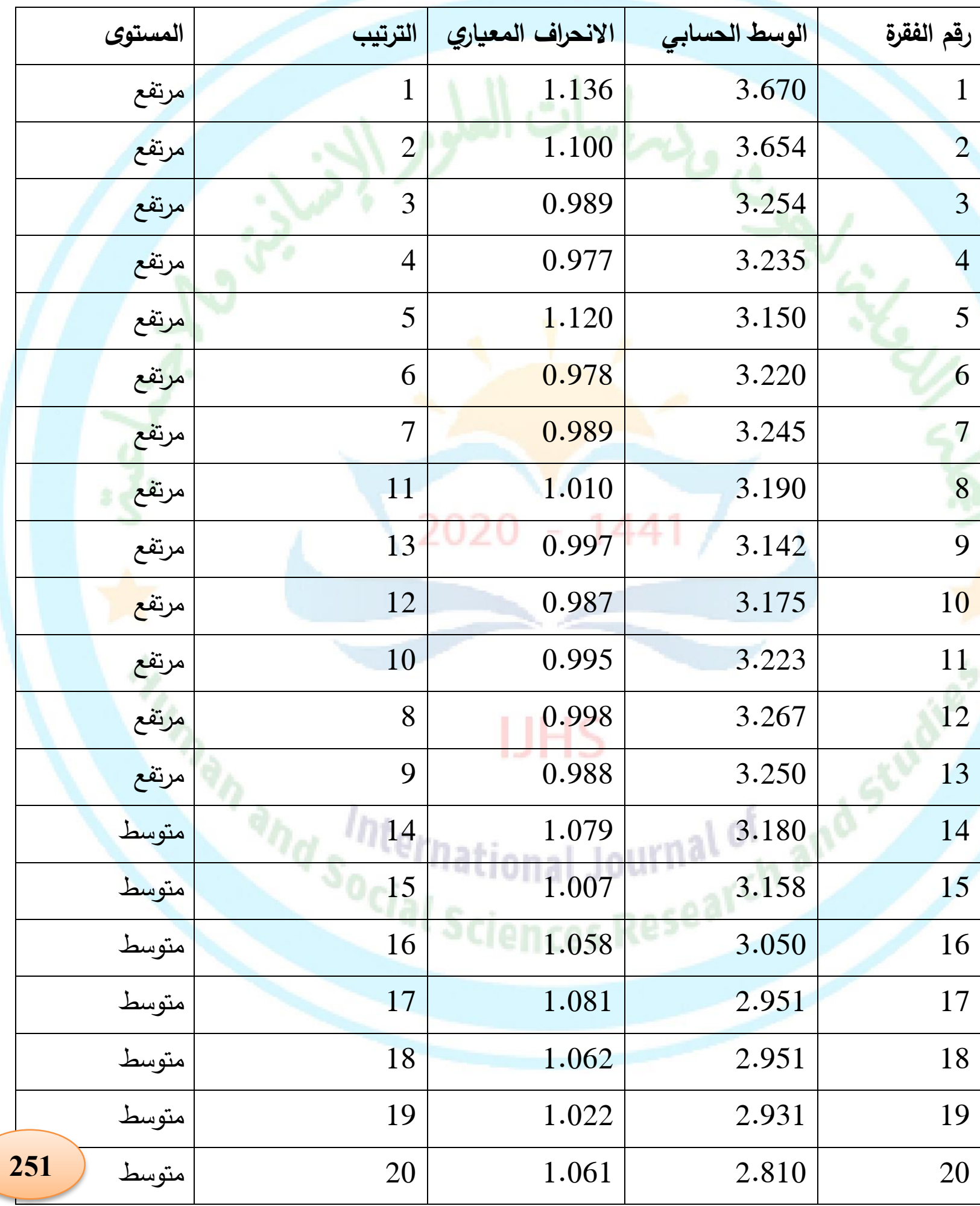

\section{International Journal of Humanities} and Social Sciences Research and Studies (IJHS) The print ISSN is: $2735-5128$ The online ISSN is: $2735-5136$ It is issued by the Excellence Pioneers Academy 
المجلة الدولية لبحوث ودراسات العلوم الإنسانية والاجتماعية (IJSH) المجلد:(الأول) العدد:(الثالث) أبريل 2021

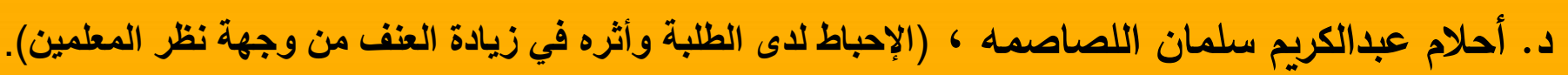

\begin{tabular}{|r|r|r|r|r|}
\hline متوسط| & 21 & 1.079 & 2.790 & 21 \\
\hline متوسط & 22 & 1.138 & 2.634 & 22 \\
\hline متوسط & 23 & 1.120 & 2.540 & 23 \\
\hline متوسط & 24 & 1.012 & 2.500 & 24 \\
\hline متوسط & 25 & 1.091 & 2.476 & 25 \\
\hline متوسط متوسط متوسط & 26 & 1.231 & 2.466 & 26 \\
\hline متوسط & 27 & 1.220 & 2.398 & 27 \\
\hline متوسط & 28 & 1.081 & 2.377 & 28 \\
\hline متوسط & 29 & 1.009 & 2.360 & 29 \\
\hline & 31 & 1.002 & 2.330 & 30 \\
\hline
\end{tabular}

الاتجاه العام: 2.946 -0.694 ( متوسط).

تثـير النتـائج في الجدول (6) إلى أن: مستوى تصورات أفراد عينـة الدراسـة جـاءت بدرجة متوسطة, حيث بلـغ المتوسط الحسابي العـام 2.946, وانحراف معياري (0.694) وتراوحت

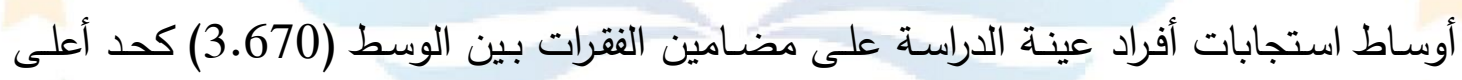
منسوب للفقرات رقم (1) والتـي تفيد أن أفراد عينـة الدراسـة مـع سلوك الثـجار مـع الآخرين, والوسط (260) كحد أدنى منسوب للفقرات رقم (13) والتي تثير إلى أنهم مع رد الإسـاءة اللفظية بإساءة بدنية.

ومسن الملاحظ في الجدول (6) أن: جميع قيم الانحرافات المعياريـة لمتغيرات كانت

متقاربة حيث تراوحت بين (1.138 - 0.998) ويعد هذا المقياس مؤشر لتجانس إجابات أفراد and Social Sciences Research and Studies (IJHS) The print ISSN is: $2735-5128$ The online ISSN is: $2735-5136$ It is issued by the Excellence Pioneers Academy 
المجلة الدولية لبحوث ودراسات العلوم الإنسانية والاجتماعية (IJSH) المجلد:(الأول) العدد:(الثالث) أبريل 2021

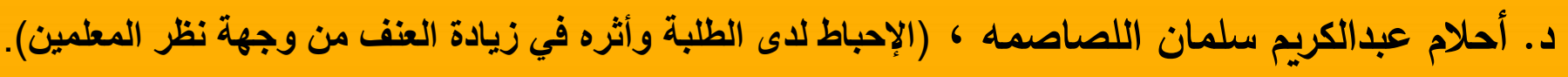

\section{مناقثة النتائج والتوصيات}

عرض النتائج: هدفت الدراسة بشكل رئيس إلى التعرف على الإحباط لاى الجماعات وأثره في

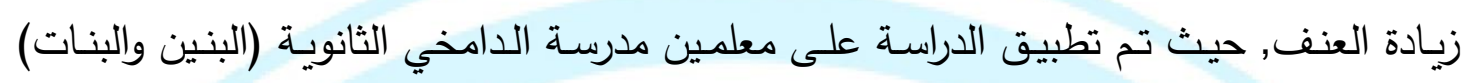
والتعرف على تصورات أفراد عينة الدراسة - معلمين - من دور الإحباط وأثره في زيادة العنف, دئرة

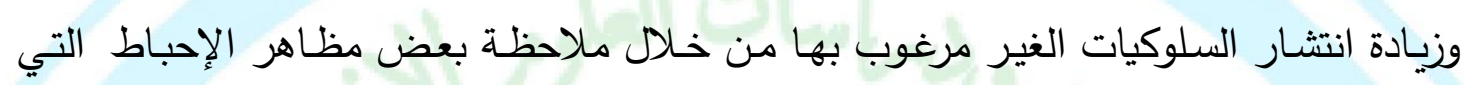
سعت على زيادة مثل تلك السلوكيات التي تميزت بالعنف.

وقد اعتمدت الدراسة لتحقيق أهدافها على الاستبان التي تم تطبيقها على عينة من معلمين, والتي تكونت من 50 معلم ومعلمة , وذلك باعتبارهم, الأكثر ملاحظة لسلوكيات العنف الناتجة عن من الن الإحباط , وفي ضوء المعايير التي اعتمدتها الدراسة, فقد أظهرت النتائج ما يلي:

مناقثــة النتـائج المتعلقـة بالأســلة: أظهرت النتائج أن المستوى العام لتصـورات أفراد عينـة الدراسة جاءت بدرجة متوسطة, حيث بلغ المتوسط الحسابي العام ( 2.946) وانحراف دعياري

وتبين من خلال النتائج أن تصورات أفراد عينة الدراسة نحو دور الإحباط وأثره في زيادة العنف

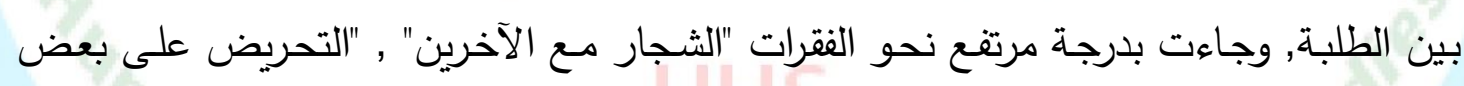

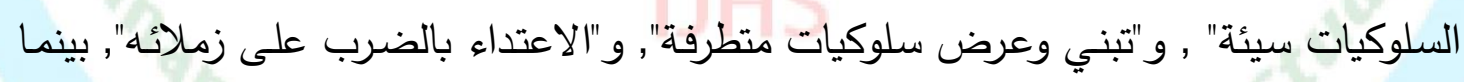
جاءت تصورات أفراد عينة الدراسة متوسطة نحو الفقرات الأخرى. وتتلقى النتيجة مع نتيجة دراسة شريف صلاح الدين (2014م) ضد الإحباط، كثيراً ما يشكو لنا الآخرون من الإحباطات التي تواجههم وتدمر حياتهم فنقف مكتوفي الأيدي، ولا ندري ماذا

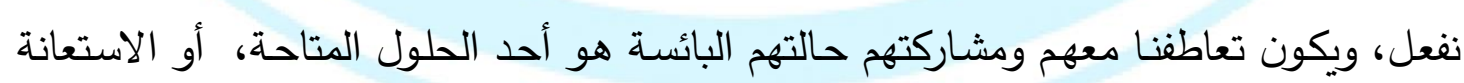

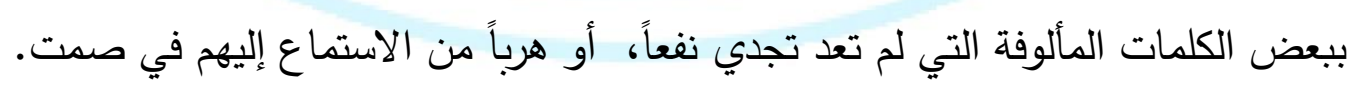

\section{International Journal of Humanities} and Social Sciences Research and Studies (IJHS) The print ISSN is: $2735-5128$ The online ISSN is: $2735-5136$ It is issued by the Excellence Pioneers Academy 
المجلة الدولية لبحوث ودراسات العلوم الإنسانية والاجتماعية (IJSH) المجلد:(الأول) العدد:(الثالث) أبريل 2021 د. أحلام عبدالكريم سلمان اللصاصمه ، (الإحباط لاى الطلبة وأثره في زيادة العنف من وجهة نظر الألئه المعلمين).

كل هذه الأفعال ستصبح مكبوتات تؤدي العنف، وتتفق مع دراسة (زيدان, 1995) والتي بينت أن العوامل الثخصية الاجتماعية وما تعرض له من الإحباط المؤثرة والمسببة لسلوك العنيف

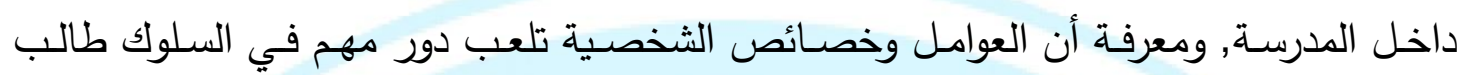
داخل المدرسة.

وكما تتفق مـع دراسة الجيلاني (2008) والتي ركزت على تتظيم الجماعات وكيفية تعلم من الجماعة وتأثر في سلوك طلبة المدرسة, وأن الجماعات تؤثر في السلوك وتغير بشكل واضح في السلوك وتؤدي إلى السلوك المنحرف إذا كانت هذه الجماعات ذات سلوكيات منحرفة.

ويرى العتوم (2008) حيث يتفق على ان الجماعة هي جزء هام من هوية الفرد وشخصيته حيث

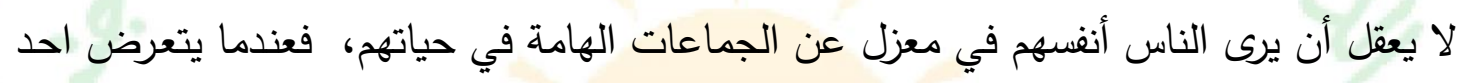

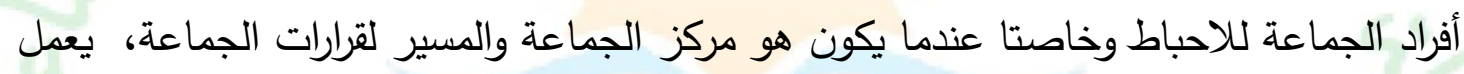
على توجيه سلوكيات أفراد الجماعة إلى العنف من أجل أن يقلل من الشعوره بالإحباط.

$$
\text { التوصيات: وهي كما يلي: - n }
$$

1. توصي الباحثة بضرورة إيلاء موضوعات في ضوء نتائج الدراسة، أي الإحباط، وأثره في زيادة العنف لدى الطلبة، وذلك لما لها من انعكاسات سلبية بالغة على فاعلية أداء الطلبة. 2. العمل على تهيئة البيئة المدرسية الملائهة، والهادفة لتعديل مثل هذه السلوكيات بها إلى ملى

$$
\text { المستويات المتوازنة. }
$$

3. للتقليل من العنف ينبغي استخدام وسائل التأثير الاجتماعي المتاحة، كالمحاضرات التثقيفية، والتوعويـة، وعقد ورش العمل، والدورات التدرببية الهادفة لتقليل من أسباب الإحباط الذي لئي

$$
\text { يتعرض له الطلبة من البيئة المحيطة. }
$$

4. دمجهم في نشاطات مدرسية في أوقات الفراغ من أجل تفريخ الكبت والتذمر الذي يتولد نتيجة

$$
\text { للإحباط. }
$$

5. زيادة التكيف مع المدرسة في رفع المعنويات من أجل تقوية شخصية طلبة المدرسة.

\section{International Journal of Humanities} and Social Sciences Research and Studies (IJHS) The print ISSN is: $2735-5128$ The online ISSN is: $2735-5136$ It is issued by the Excellence Pioneers Academy 
المجلة الدولية لبحوث ودراسات العلوم الإنسانية والاجتماعية (IJSH) المجلد:(الأول) العدد:(الثالث) أبريل 2021

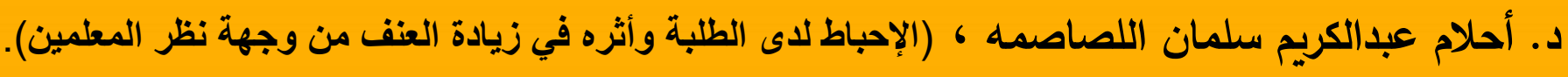

\section{المراجع.}

1. أحمد عكاشة (1982): علم النفس الفسيولوجي، مكتبة الأنجلو المصرية, القاهره.

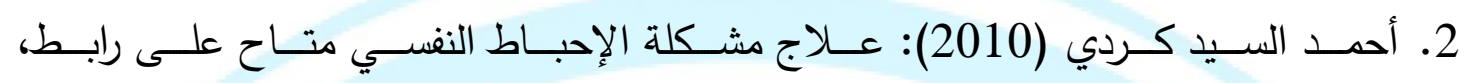
http://www.mishooo.net/vb/t162268.html

3. حسان الجيلاني، "الجماعات" (دراسة نفسية اجتماعية للجماعات غير الرسمية) بوزريعة، الجزائر ، دار هومة للطباعة والنشر والتوزيع(2008). 4. شريف صلاح الدين (2014): ضد الإحباط, أطلس للنشر والإنتاج الإعلامي. 5. زيدان, عرفات (1995): العوامل الثخصية الاجتماعية المؤثرة في سلوك العنف لدى طلبة الجامعة، مجلة الخدمه الاجتماعية المعهد العالي للخدمه الاجتماعية, القاهرة . 6. عايد عواد الوريكات(2004): نظريات علم الجريمة, دار الثروق للنشر والتوزيع، عمان. 7. عدنان يوسف العتوم (2008): علم النفس الجماعة، إثراء للنشر والتوزيع, عمان .

8. Facerman, L, E. 1994. Emotions and Behavior, Peter press, Moscow, Russia.

9. Boeco, V,V. 1996. Energy of emotions in communication, peter press, Mosow, Runssia.

10.Wallace and Walf, (1991), Contemporary Sociological theory: Continuing the classica tradition. New Jersey. U. S. A. 


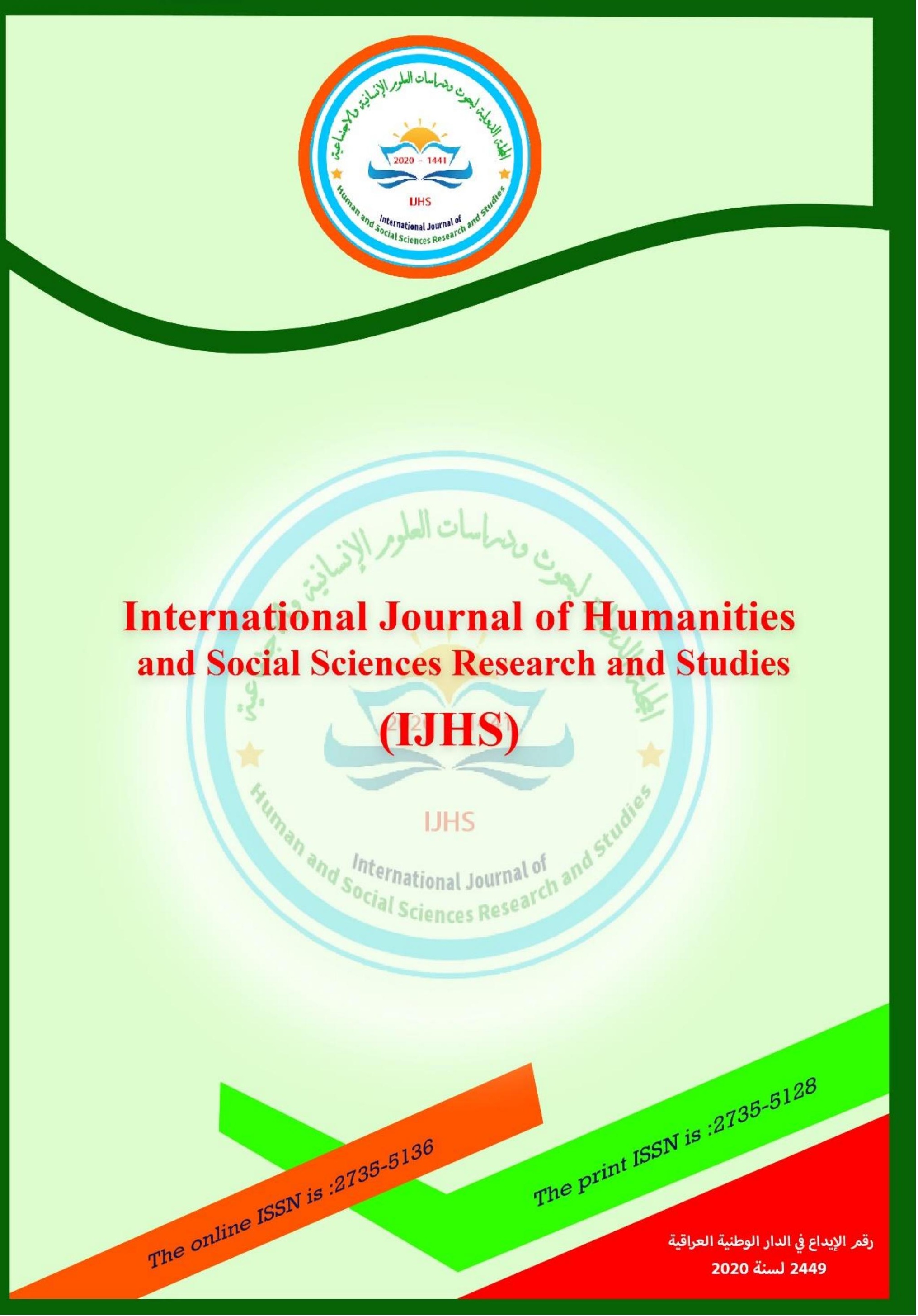

